Research Paper

\title{
Evaluation of Blood Cell Attachment on Er:Yag Laser Applied Root Surface Using Scanning Electron Micros- copy
}

\author{
Ali CEKICI ${ }^{\circledR}$, Ilay MADEN², Sercan YILDIZ2, Tangul SAN², Gulden ISIK ${ }^{1}$ \\ 1. Istanbul University Faculty of Dentistry Department of Periodontology; \\ 2. Marmara University Faculty of Medicine Department of Histology; \\ 3. RWTH Aachen, AALZ.
}

$\triangle$ Corresponding author: Ali Cekici, Istanbul University Faculty of Dentistry Department of Periodontology 3rd Floor 34093 Capa Istanbul Turkey. Email: cekici@istanbul.edu.tr (email can be published). Fax: +90 2125340807.

(c) Ivyspring International Publisher. This is an open-access article distributed under the terms of the Creative Commons License (http://creativecommons.org/ licenses/by-nc-nd/3.0/). Reproduction is permitted for personal, noncommercial use, provided that the article is in whole, unmodified, and properly cited.

Received: 2012.09.17; Accepted: 2013.02.28; Published: 2013.03.15

\begin{abstract}
Background: Periodontal regeneration is dependent on the uninterrupted adhesion, maturation and absorption of fibrin clots to a periodontally compromised root surface. The modification of the root surface with different agents has been used for better fibrin clot formation and blood cell attachment. It is known that Er:YAG laser application on dentin removes the smear layer succesfully.

Aim: The aim of this study is to observe blood cell attachment and fibrin network formation following ER:YAG laser irradiation on periodontally compromised root surfaces in comparison to chemical root conditioning techniques in vitro.

Materials and methods: 40 dentin blocks prepared from freshly extracted periodontally compromised hopeless teeth. Specimens were divided in 5 groups; those applied with PBS, EDTA, Citric acid and Er:YAG. They were further divided into two groups: those which had received these applications, and the control group. The specimens were evaluated with scanning electron microscope and micrographs were taken. Smear layer and blood cell attachment scoring was performed.

Results: In the Er:YAG laser applied group, smear layer were totally removed. In the blood applied specimens, better fibrin clot formation and blood cell attachment were observed in the Er:YAG group. In the group that had been applied with citric acid, the smear layer was also removed. The smear layer could not be fully removed in the EDTA group.

Conclusion: Er:YAG laser application on the root dentin seems to form a suitable surface for fibrin clot formation and blood cell attachment. Further clinical studies to support these results are necessitated.
\end{abstract}

Key words: Periodontal regeneration, In vitro, Erbium yag laser, Scanning electron microscopy.

\section{Introduction}

Periodontal regeneration is a challenge for periodontal therapy. Periodontal therapy includes removal of plaque, calculus and root planing the affected root surface, which usually results in the re- moval of diseased cementum. ${ }^{1}$ Depending on the severity and the depth of the disease on the root surface, this procedure may remove the entire cementum layer, leaving dentin in contact with the periodontium 
tissues. It is also well known that the healing following the removal of diseased cementum by scaling and root planing results mostly from the formation of the epithelial attachment rather than connective tissue. The initial wound healing starts with the formation of fibrin clot between the root surface and the gingival connective tissue. Blood elements imposed onto the root surface during surgery and at wound closure must establish an attachment that endures physiologic and other forces acting on the tooth and gingival flap interface. ${ }^{2-4}$ It is also well known that the formation of smear layer after scaling and root planing procedures can eliminate the fibrin network stabilization by the cytotoxic residue from microorganisms, plaque or calculi in its constitution.5, 6 Because of this reason, the effects of various agents to remove the smear layer and expose more collagen fibers on the root surface have been tested in several studies.5, 7-10 All this effort was to increase the clot linkage strength, since it is known that the connection between fibrin from the clot and collagen on the root surface can prevent epithelial down-growth. This way, a scaffold can be formed for cell development and better mature collagen fiber attachment. ${ }^{11}$

Most of the in-vitro studies presented successful results in the removal of the smear layer by different root conditioning techniques.5, 7-10 However, clinical studies did not manage to show a significant advantage of root conditioning by means of re-attachment. ${ }^{12-17}$

In recent years there has been an increasing interest in laser therapy as an adjunct to periodontal treatment. In studies evaluating the effect of lasers on root surface conditioning, successful smear layer removal has been shown. This effect was more intense with the use of Er:YAG laser. ${ }^{10,}{ }^{18-20}$ In some studies blood was applied on the conditioned root surfaces to mimic the periodontal surgery procedure and blood components attachment was observed. When different lasers were compared, root surfaces treated with ER:YAG laser presented a better adhesion of blood cell attachment and a better fibrin network formation. ${ }^{18,19}$ In a separate study, evaluation of blood cell attachment on EDTA-treated root surfaces was not found successful. ${ }^{21}$ When a comparison was carried out with different chelating agents, citric acid application on the root surfaces resulted in a more stable clot formation on the root surface than tetracyclin HCL, sodium citrate and EDTA. ${ }^{22}$ Although a decent amount of information is available on root surface conditioning with conventional techniques and lasers, a comparison between conventional methods and laser application has not yet been completed.
The aim of this study is to evaluate blood cell attachment and fibrin network formation following ER:YAG laser irradiation on periodontally-compromised root surfaces in comparison to conventional root conditioning techniques in vitro.

\section{Materials and Methods}

\section{Collection and Preparation of Specimens}

This study was approved by the Ethics Committee of Istanbul University Faculty of Medicine, Turkey. All of the parients who agreed to volunteer for this study signed a detailed informed conset form in advance.

20 human mandibular molar teeth from 17 systemically healthy, non-smoking patients were extracted at the Istanbul University Faculty of Dentistry Department of Periodontology Clinics. Extracted teeth had severe periodontal disease exhibiting 3rd grade mobility and probing depth greater than $8 \mathrm{~mm}$ where prognosis was considered hopeless. All teeth were absent of fillings, restorations and caries. After extraction, teeth were cleaned with distilled water and stored in phospate-buffered saline (PBS) at $4^{\circ} \mathrm{C}$ until the treatments were performed.

Two parallel grooves were prepared on the proximal root surface of each tooth, one at the cemento-enamel junction, the other approximately $4 \mathrm{~mm}$ apical to the first groove. The area between two grooves on each root surface were planed with Gracey curettes 5/6 (Gracey curettes no. 5/6, Hu Friedy Co., Chicago, USA), by means of 50 apical-to-cervical traction movements. Scaling and root planing were performed by the same experienced operator. Using a high-speed cylindrical bur under copious water irrigation, all roots were crosscut to separate them from the crown. After this, all roots were cut lengthwise in the mesio-distal orientation. Two dentin blocks from each tooth approximately $4 \times 4 \times 1 \mathrm{~mm}$ in size were prepared. Samples obtained from each tooth were stored in an identified bottle containing PBS.

\section{Experimental Procedures}

Bottles were randomly assigned to 5 groups, with a total of 8 samples in each group.

The following treatments were performed: (A) irrigation in $10 \mathrm{ml}$ PBS; (B) application of $24 \%$ EDTA gel (PrefGel, Straumann) with a cotton-pellet for 2 minutes followed by saline irrigation for 10 seconds; 8 , 22 (C) application of $25 \%$ citric acid pH 1.5 with a cotton pellet followed by saline irrigation for $10 \mathrm{sec}-$ onds; ${ }^{22}$ (D) application of pulsed Er:YAG laser with a wavelength of $2.94 \mu \mathrm{m}$ (Fotona HT Fidelis, Fotona d.d., Ljubljana, SLOVENIA) according to the following parameters: energy at $80 \mathrm{~mJ}$ as indicated on the 
display, repetition rate of $20 \mathrm{~Hz}$ for $15 \mathrm{~s}$, with a pulse duration of $100 \mu$ s, fluency of each pulse $15.92 \mathrm{~J} / \mathrm{cm}^{2}$ and specimens were immediately irrigated with $10 \mathrm{ml}$ saline solution; ${ }^{10}$ (E) application of pulsed Er:YAG laser with wavelength of $2.94 \mu \mathrm{m}$ (Fotona HT Fidelis, Fotona d.d., Ljubljana, SLOVENIA) according to the following parameters: energy at $120 \mathrm{~mJ}$ as indicated on the display, repetition rate of $20 \mathrm{~Hz}$ for $15 \mathrm{~s}$, with a pulse duration of $100 \mu \mathrm{s}$, fluency of each pulse 23.88 $\mathrm{J} / \mathrm{cm}^{2}$, and specimens were immediately irrigated with $10 \mathrm{ml}$ saline solution. (Figure 1)

Four of the samples in each bottle was exposed to whole peripheral blood obtained from a healthy male donor following treatments. The blood was allowed to clot for 20 minutes in a humidified chamber at $37^{\circ} \mathrm{C}$. Blocks were rinsed after clotting, 3 times with PBS for 3 minutes. Washes and rinses were performed on a tabletop shaker at low speed. These samples were used to determine the blood cell attachment and fibrin network formation. Remaining samples were used to determine the effects of conditioning on root surface.

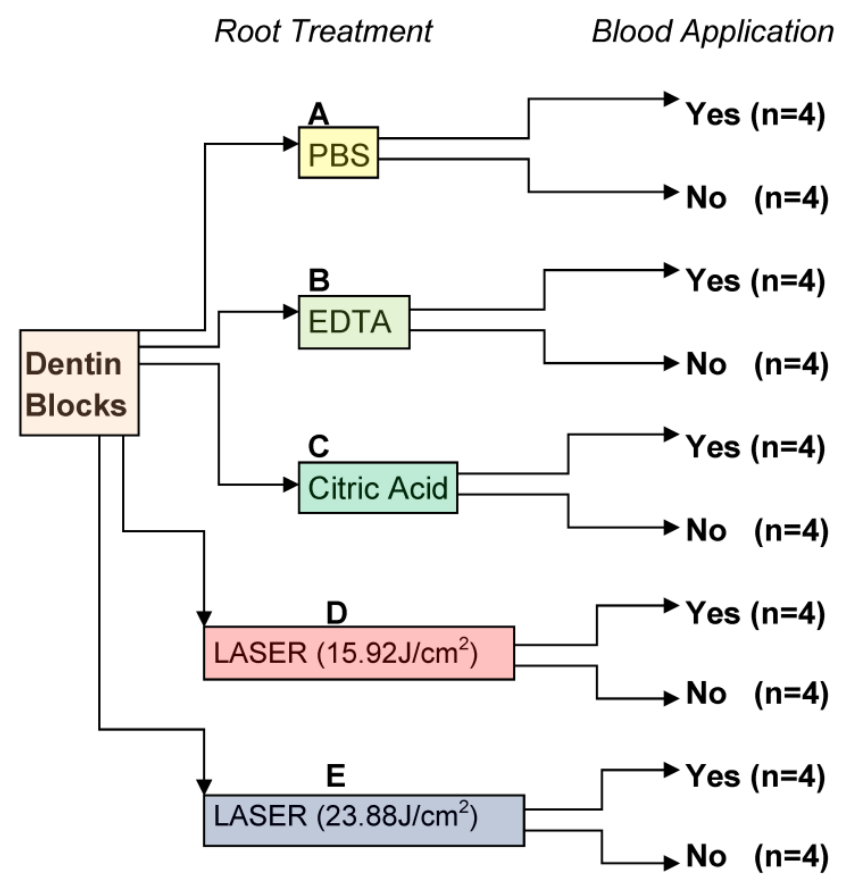

Figure I. Experimental design. PBS, phosphate buffered saline; EDTA, ethylenediaminetetraacetic acid; Citric acid; Er:YAG laser $15.92 \mathrm{~J} / \mathrm{cm}^{2}$; Er:YAG laser $23.88 \mathrm{~J} / \mathrm{cm}^{2}$.

\section{Laser Irradiation}

The specimens were irradiated by a handpiece with a non-contact tip with a beam radius of $0.8 \mathrm{~mm}$. The pulsed Er:YAG laser was used manually with the tip positioned perpendicularly and at 7-8 $\mathrm{mm}$ distance from the suface of the dentin, simulating its use during periodontal surgery. The specimens were irradiated under water irrigation by continuous movement of the tip.

\section{SEM analysis}

Following treatments, samples from all groups were fixed in $2.5 \%$ gluteraldehyde in a phosphate buffer ( $\mathrm{pH} 7.3$ ) for $24 \mathrm{~h}$ and then washed three times for 10 minutes in the phosphate buffer. The specimens were then dehydrated in a graded series of aqueous ethanol solutions $(70 \%, 85 \%, 95 \%$ and $100 \%$ ethanol) for 10 minutes each. The samples were dried overnight at room temperature. They were mounted on aluminum stubs and sputter-coated with a gold-palladium alloy under vacuum for $120 \mathrm{~s}$.

A representitive photomicrograph was obtained from all samples at 1000X and 3500X. All photomicrographs were obtained through a scanning electron microscope (SEM) operated at $20 \mathrm{kV}$ (Jeol JSM-820, Jeol).

On the photomicrographs taken, scoring for blood component adhesion (BCA) and smear layer removal (SLR) were performed. The scoring was performed by a single blinded operator, who was previously trained.

$B C A$ scoring ${ }^{6}$

0 - Absence of fibrin network

1- Scarce fibrin network and/or blood

2- Moderate fibrin network and moderate quantity of blood cells

3- Dense fibrin network and trapped blood cells

SLR scoring 10

1- No smear layer and open dentinal tubules

2- No smear layer and partially open dentinal tubules

3- No smear layer and obliterated dentinal tubules

4- Moderate smear layer and open dentinal tubules

5- Moderate smear layer and partially open dentinal tubules

6- Heavy smear layer and open dentinal tubules

7- Heavy smear layer and partially open dentinal tubules

\section{Statistical Analysis}

Scores were independently analyzed for each group. Groups were compared to each other for both SLR and BCA scores. Non-parametric Kruskal-Wallis test $(P<0.05)$ was employed to compare the rank sums of the evaluated groups. Statistical evaluation was performed by using SPSS v.11.5 statistical program package. (SPSS v.11.5, IBM, Chicago, IL.) 


\section{Results}

In the control group (group A) and EDTA applied group (group B) one sample presented open dental tubules with a heavy smear layer. Three other samples showed partially open dental tubules with a

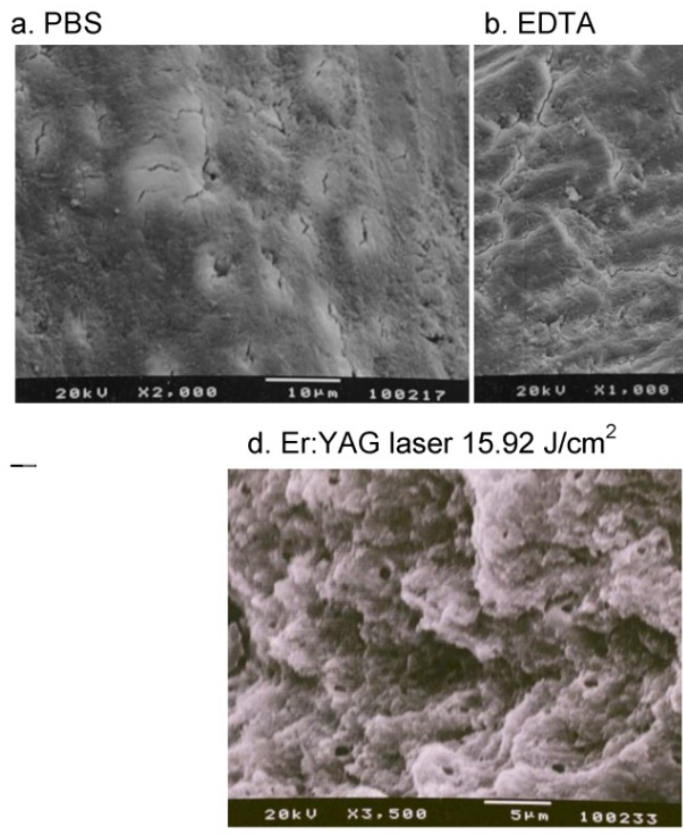

heavy smear layer. (Figure 2) In group A there was no sign of fibrin network. In group B, two of the samples showed very few blood cells within the fibrin network. The remaining two samples in the same group showed a moderate level of blood cell attachment. (Figure 3)

c. Citric acid

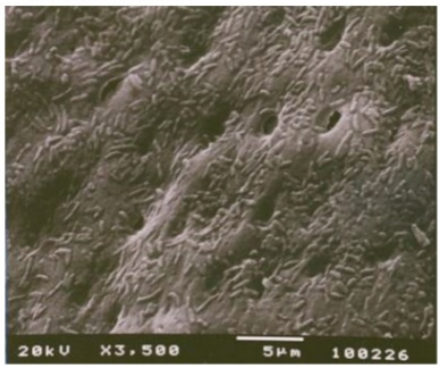

e. Er:YAG laser $23.88 \mathrm{~J} / \mathrm{cm}^{2}$

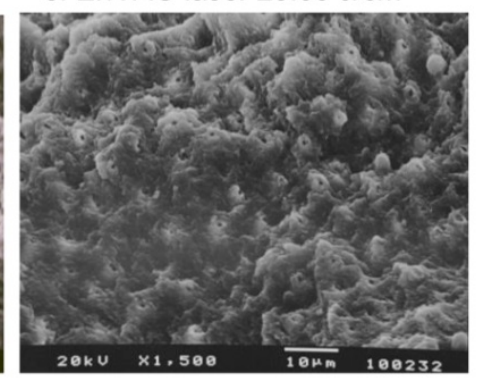

Figure 2. Effect of surface treatment on dentin. Instrumented dentin exhibited a smear layer (a). The smear layer still obscured the dentinal tubules following conditioning with EDTA (b). The smear layer was removed following conditioning with citric acid exposing the dentinal tubules (c). The smear layer was removed following Er:YAG laser $15.92 \mathrm{~J} / \mathrm{cm}^{2}$ and $23.88 \mathrm{~J} / \mathrm{cm}^{2}$ exposing the dentinal tubules and surface roughness is increased $(\mathrm{d}, \mathrm{e})$.

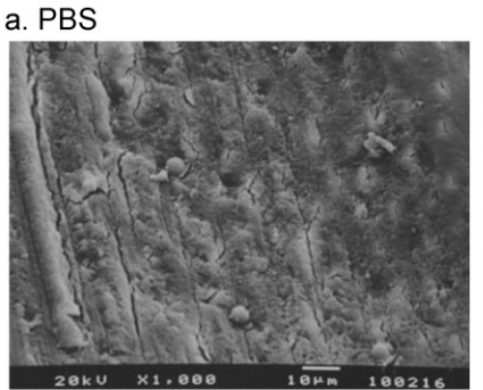

b. EDTA

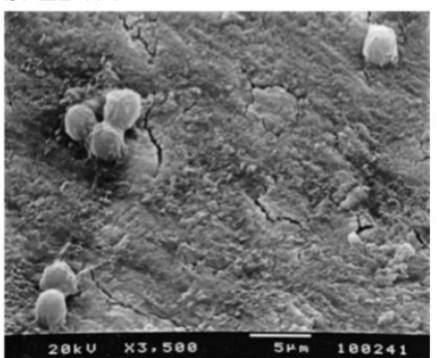

c. Citric acid

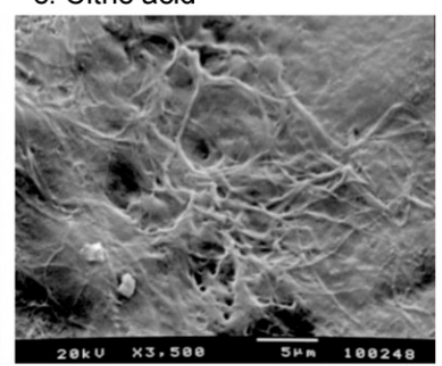

e. Er:YAG laser $23.88 \mathrm{~J} / \mathrm{cm}^{2}$

d. Er:YAG laser $15.92 \mathrm{~J} / \mathrm{cm}^{2}$

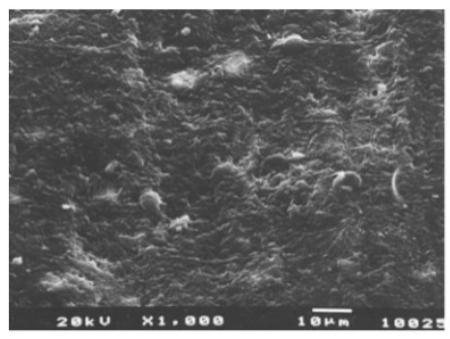

Figure 3. Effect of surface treatment on fibrin clot formation on dentin. A few of blood cells are present on the surface following PBS conditioning (a). Some blood cells, and a weak fibrin network formed following EDTA conditioning (b). Dense fibrin network formation and embedded blood cells can be seen following citric acid conditioning (c). Dense fibrin network formation and increased blood cell attachment are observed following Er:YAG irradiation at $15.92 \mathrm{~J} / \mathrm{cm}^{2}$ (d). Less fibrin network and blood cell attachment are observed following Er:YAG irradiation at $23.88 \mathrm{~J} / \mathrm{cm}^{2}(\mathrm{e})$. 
In the citric acid applied group (group C) one sample showed partially open dental tubules with no smear layer. The remaining three samples presented fully open dental tubules with no smear layers visible. (Figure 2) In this group, in one of the samples there were very few blood cells within a fibrin network. The other three samples showed moderate levels of blood cell attachment. (Figure 3)

In the laser groups (groups D and E) dental tubules were fully open and there were no signs of smear layers in all samples. (Figure 2) In group D one of the samples showed moderate levels of blood cell attachment. Three of the samples presented dense fibrin networks and trapped blood cells. In group E, in one of the samples there were very few blood cells, two samples showed moderate quantity of blood cell attachment, and one sample showed dense fibrin network and trapped blood cells. (Figure 3)

When the groups were compared, following the analysis of SLR scoring we observed that groups C, D and $\mathrm{E}$ got lower scores than groups $\mathrm{A}$ and $\mathrm{B}$. This finding was statistically significant. (Table 4)

When BCA scoring was analysed we observed that groups $C, D$ and $E$ got significantly higher scores than group $\mathrm{A}$. Groups $\mathrm{C}$ and D got significantly higher scores than group B. Group D also got statistically higher scores than group C. (Table 3 )

Table I. Frequencies of BCA score in groups. $(n=4)$

\begin{tabular}{llllll}
\hline Scores & $\mathrm{A}$ & $\mathrm{B}$ & $\mathrm{C}$ & $\mathrm{D}$ & $\mathrm{E}$ \\
\hline 0 & 4 & 0 & 0 & 0 & 0 \\
1 & 0 & 2 & 1 & 0 & 1 \\
2 & 0 & 2 & 3 & 1 & 2 \\
3 & 0 & 0 & 0 & 3 & 1 \\
\hline
\end{tabular}

Table 2. Frequencies of SLR score in groups. $(n=4)$

\begin{tabular}{llllll}
\hline Scores & A & B & C & D & E \\
\hline 1 & 0 & 0 & 3 & 4 & 4 \\
2 & 0 & 0 & 1 & 0 & 0 \\
3 & 0 & 0 & 0 & 0 & 0 \\
4 & 0 & 0 & 0 & 0 & 0 \\
5 & 0 & 0 & 0 & 0 & 0 \\
6 & 1 & 1 & 0 & 0 & 0 \\
7 & 3 & 3 & 0 & 0 & 0 \\
\hline
\end{tabular}

Table 3. Median values and comparison of BCA scores between groups.

\begin{tabular}{lll}
\hline Groups & Median & P \\
\hline A & 0 & A and C, D, E p $<0.05$ \\
B & 1.5 & B and D p $<0.05$ \\
C & 2 & C and D p $<0.05$ \\
D & 3 & - \\
E & 2 & - \\
\hline
\end{tabular}

Table 4. Median values and comparison of SLR scores between groups.

\begin{tabular}{lll}
\hline Groups & Median & P \\
\hline A & 7 & A and C, D, E p $<0.05$ \\
B & 7 & B and C, D, E p $<0.05$ \\
C & 1 & - \\
D & 1 & - \\
E & 1 & - \\
\hline
\end{tabular}

\section{Discussion}

In this study a comparison between root surface conditioning techniques and blood cell attachment to these surfaces was performed. Considering the increasingly developing interest in dental laser applications, evaluation of the effects of this technology by comparing it to the previously described chemical root surface conditioning methods in an in vitro model was designed.

In our study, blocks from the root surfaces were prepared following root planning but before the application of PrefGel, citric acid, and lasers. It should be mentioned that if the test conditions were applied before blocks were prepared, it would have been more likely to mimic the clinical conditions. On the other hand, by applying PrefGel, citric acid, and lasers following specimen preparation, it was easier to assign the blocks to different groups randomly. In group A we observed that following manual root planing alone, a heavy smear layer was present in accordance with previous study findings. ${ }^{10,} 23$ (Table 4)

In group B, smear layers were still visible covering most of the dentin tubules following EDTA application.(Figure 2) This finding was parallel to the findings in the study by Baker, et al., ${ }^{24}$ but not with

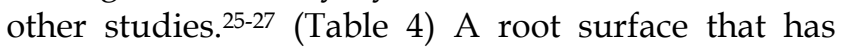
been exposed to the pocket environment for a long time becomes hypermineralized, meaning that the mineral content is increased. ${ }^{28-30}$ It may be because of this reason that we were not able to observe the removal of smear layers with EDTA application in our specimens. 
In group $C$ the smear layer was totally removed (Figure 2) in accordance with the findings in several other studies. ${ }^{31-34}$

In groups $\mathrm{D}$ and $\mathrm{E}$, application with both power settings of Er:YAG laser exhibited total removal of smear layer. (Figure 2) (Table 4) The topography of the root surface with Er:YAG laser was morphologically different than with citric acid modification. Although laser irradiation did cause irregularities on the root surface, there were no carbonization, craters, cracks or fractures observed, in parallel to the findings in similar studies. ${ }^{35-37}$

When evaluating the blood cell attachment and fibrin network formation, groups $\mathrm{A}$ and $\mathrm{B}$ exhibited the poorest outcome, while groups $\mathrm{C}, \mathrm{D}$, and $\mathrm{E}$ presented significantly higher amounts of blood cell attachment to the root surfaces. (Figure 3) (Table 3) These findings are in accordance with a similar study, ${ }^{19}$ but contradict a study by Theodoro et. al. where Er:YAG laser is applied at a power setting of $7.6 \mathrm{~J} / \mathrm{cm}^{2}$ and $12.9 \mathrm{~J} / \mathrm{cm}^{2}$ per pulse in two different groups. ${ }^{18}$ In the present study our lowest power setting where we observed greater blood cell attachment and fibrin network formation was $15.9 \mathrm{~J} / \mathrm{cm}^{2}$ per pulse.

One of our laser applied groups (group D) presented the best outcome in terms of blood cell attachment and fibrin network formation compared to the other groups.(Table 4) This finding is promising due to the potential of Er:YAG laser application in periodontology.

There may be several explanations for this effect. One of the possible scenarios is that the formation of smear layers, which consist of cytotoxic residues from microorganisms, plaque or calculi, can eliminate the fibrin network stabilization,, 6 and the presence of endotoxins and bacteria could inhibit the adhesion of plasma proteins on the root surface. ${ }^{2}$ Er:YAG laser is known to have high bactericidal effects when used even at low energy levels. ${ }^{38}$ Furthermore, the Er:-YAG laser irradiation promotes a removal of mineralized tissues producing holes and bumps and, consequently, promoting irregular root surfaces and a larger exposure area of collagen fiber. The exposure of collagen fiber could facilitate the adhesion and formation of primary homeostatic buffers through the adhesion of plaques to the exposed collagen. ${ }^{18}$

Additionally our results revealed that ER:YAG laser application increased surface roughness dramatically. This is probably due to the wavelength of Er:YAG which is highly absorbed by the water spray on the surface and the water molecules present in the mineralized tissue, causing hard tissue particles to be expelled through micro explosions, a process known as ablation. As a result of ablation, a larger exposure area for collagen fiber attachment due to irregular root surfaces is formed. ${ }^{10,39} \mathrm{In}$ addition to this, the root surface properties could have played a certain role in the cell retention. Some studies have demonstrated that polymorphonuclear cells prefer to adhere to rough surfaces rather than smooth ones. ${ }^{40,41}$

On the other hand increasing the roughness of the root surface with the use of Er:YAG laser could result in the possible increase in the retention of bacterial plaque if exposed. Further in vitro and clinical studies should address the possible risk of bacteria colonization on the Er:YAG laser irradiated root surface concerning the maintenance of a longterm periodontal regeneration treatment.

In this study it was not possible to evaluate the viability of the blood cells on the root surface or to distinguish the predominant cell type. Although it is known that in the early phases of periodontal wound healing following flap surgery, aggregates of erythrocytes interspersed in a granular precipitate of plasma proteins may be observed immediately following wound closure. This is followed by the intercellular matrix with fibrin formation on the dentin surface and neutrophil infiltration throughout the wound. ${ }^{3}$

The results of our study suggest that the Er:YAG laser can be safely used to condition diseased root surfaces effectively. Er:YAG lasers, when set to a power setting of $80 \mathrm{mj}$ with $100 \mu$ s pulse duration, created a more suitable surface for blood cell adhesion and fibrin network formation than application of Er:YAG laser at power setting of $120 \mathrm{mj}$, EDTA or citric acid. Further clinical studies should address if the use of Er:YAG lasers in different periodontal regeneration techniques would support the findings of this study.

\section{Acknowledgements}

The authors declare that they have no conflict of interest. Authors would also like to thank Dr. Zafer Kazak for his contribution in supplying Er:YAG laser for this study.

\section{Competing Interests}

The authors have declared that no competing interest exists.

\section{References}

1. Jones WA, O'Leary TJ. The effectiveness of in vivo root planing in removing bacterial endotoxin from the roots of periodontally involved teeth. J Periodontol 1978;49:337-342.

2. Wikesjo UM, Nilveus RE, Selvig KA. Significance of early healing events on periodontal repair: a review. J Periodontol 1992;63:158-165.

3. Wikesjo UM, Crigger M, Nilveus R, Selvig KA. Early healing events at the dentin-connective tissue interface. Light and transmission electron microscopy observations. J Periodontol 1991;62:5-14. 
4. Wikesjo UM, Claffey N, Nilveus R, Egelberg J. Periodontal repair in dogs: effect of root surface treatment with stannous fluoride or citric acid on root resorption. J Periodontol 1991;62:180-184.

5. Polson AM, Proye MP. Fibrin linkage: a precursor for new attachment. J Periodontol 1983;54:141-147.

6. Polson AM, Frederick GT, Ladenheim S, Hanes PJ. The production of a root surface smear layer by instrumentation and its removal by citric acid. J Periodontol 1984;55:443-446.

7. Steinberg AD, Willey R. Scanning electron microscopy observations of initial clot formation on treated root surfaces. I Periodontol 1988;59:403-411.

8. Baker PJ, Rotch HA, Trombelli L, Wikesjo UM. An in vitro screening model to evaluate root conditioning protocols for periodontal regenerative procedures. J Periodontol 2000;71:1139-1143.

9. Isik AG, Tarim B, Hafez AA, Yalcin FS, Onan U, Cox CF. A comparative scanning electron microscopic study on the characteristics of demineralized dentin root surface using different tetracycline $\mathrm{HCl}$ concentrations and application times. J Periodontol 2000;71:219-225.

10. Theodoro LH, Zezell DM, Garcia VG, et al. Comparative analysis of root surface smear layer removal by different etching modalities or erbium:yttrium-aluminum-garnet laser irradiation. A scanning electron microscopy study. Lasers Med Sci 2009;25:485-491.

11. Bal B, Eren K, Balos K. Effects of various root surface treatments on initial clot formation: a scanning electron microscope study. J Nihon Univ Sch Dent 1990;32:281-293.

12. Register AA. Bone and cementum induction by dentin, demineralized in situ. J Periodontol 1973;44:49-54.

13. Ririe CM, Crigger M, Selvig KA. Healing of periodontal connective tissues following surgical wounding and application of citric acid in dogs. J Periodontal Res 1980;15:314-327.

14. Wikesjo UM, Baker PJ, Christersson LA, et al. A biochemical approach to periodontal regeneration: tetracycline treatment conditions dentin surfaces. I Periodontal Res 1986;21:322-329.

15. Garrett JS, Crigger M, Egelberg J. Effects of citric acid on diseased root surfaces. J Periodontal Res 1978;13:155-163.

16. Wikesjo UM, Claffey N, Christersson LA, et al. Repair of periodontal furcation defects in beagle dogs following reconstructive surgery including root surface demineralization with tetracycline hydrochloride and topical fibronectin application. J Clin Periodontol 1988;15:73-80.

17. Alger FA, Solt CW, Vuddhakanok S, Miles K. The histologic evaluation of new attachment in periodontally diseased human roots treated with tetracycline-hydrochloride and fibronectin. J Periodontol 1990;61:447-455.

18. Theodoro LH, Sampaio JE, Haypek P, Bachmann L, Zezell DM, Garcia VG. Effect of Er:YAG and Diode lasers on the adhesion of blood components and on the morphology of irradiated root surfaces. J Periodontal Res 2006;41:381-390.

19. Oliveira GJ, Theodoro LH, Marcantonio Junior E, Sampaio JE, Marcantonio RA. Effect of Er,Cr:YSGG and Er:YAG laser irradiation on the adhesion of blood components on the root surface and on root morphology. Braz Oral Res. 2012;26:256-262.

20. Theodoro LH, Haypek P, Bachmann L, et al. Effect of ER:YAG and diode laser irradiation on the root surface: morphological and thermal analysis. J Periodontol 2003;74:838-843.

21. Leite FR, Moreira CS, Theodoro LH, Sampaio JE. Blood cell attachment to root surfaces treated with EDTA gel. Braz Oral Res 2005;19:88-92.

22. Leite FR, Sampaio JE, Zandim DL, Dantas AA, Leite ER, Leite AA. Influence of root-surface conditioning with acid and chelating agents on clot stabilization. Quintessence Int 2010;41:341-349.

23. Coldiron NB, Yukna RA, Weir J, Caudill RF. A quantitative study of cementum removal with hand curettes. J Periodontol 1990;61:293-299.

24. Baker DL, Stanley Pavlow SA, Wikesjo UM. Fibrin clot adhesion to dentin conditioned with protein constructs: an in vitro proof-of-principle study. J Clin Periodontol 2005;32:561-566.

25. Blomlof JP, Blomlof LB, Lindskog SF. Smear layer formed by different root planing modalities and its removal by an ethylenediaminetetraacetic acid gel preparation. Int $J$ Periodontics Restorative Dent 1997; 17:242-249.

26. Blomlof J. Root cementum appearance in healthy monkeys and periodontitis-prone patients after different etching modalities. J Clin Periodontol 1996;23:12-18.

27. Blomlof J, Blomlof L, Lindskog S. Effect of different concentrations of EDTA on smear removal and collagen exposure in periodontitis-affected root surfaces. J Clin Periodontol 1997;24:534-537.

28. Wirthlin MR, Pederson ED, Hancock EB, Lamberts BL, Leonard EP. The hypermineralization of diseased root surfaces. J Periodontol 1979;50:125-127.
29. Selvig KA, Hals E. Periodontally diseased cementum studied by correlated microradiography, electron probe analysis and electron microscopy. J Periodontal Res 1977;12:419-429.

30. Selvig KA, Selvig SK. Mineral content of human and seal cementum. J Dent Res 1962;41:624-632.

31. Bergenholtz A, Babay N. Scanning electron microscopy of the root surface texture of extracted periodontally diseased teeth following various etching and chelating regimens. Int J Periodontics Restorative Dent 1998;18:171-179.

32. Higashi $\mathrm{T}$, Okamoto $\mathrm{H}$. The effect of ultrasonic irrigation before and after citric acid treatment on collagen fibril exposure: an in vitro SEM study. $J$ Periodontol 1995;66:887-891.

33. Lafferty TA, Gher ME, Gray JL. Comparative SEM study on the effect of acid etching with tetracycline $\mathrm{HCl}$ or citric acid on instrumented periodontally-involved human root surfaces. J Periodontol 1993;64:689-693.

34. Cogen RB, Garrison DC, Weatherford TW. Effect of various root surface treatments on the viability and attachment of human gingival fibroblasts. J Periodontol 1983;54:277-282.

35. Aoki A, Miura M, Akiyama F, et al. In vitro evaluation of Er:YAG laser scaling of subgingival calculus in comparison with ultrasonic scaling. $J$ Periodontal Res 2000;35:266-277.

36. Folwaczny M, Mehl A, Haffner C, Benz C, Hickel R. Root substance removal with Er:YAG laser radiation at different parameters using a new delivery system. J Periodontol 2000;71:147-155.

37. Yamaguchi H, Kobayashi K, Osada R, et al. Effects of irradiation of an erbium:YAG laser on root surfaces. J Periodontol 1997;68:1151-1155.

38. Ando Y, Aoki A, Watanabe H, Ishikawa I. Bactericidal effect of erbium YAG laser on periodontopathic bacteria. Lasers Surg Med 1996;19:190-200.

39. Feist IS, De Micheli G, Carneiro SR, Eduardo CP, Miyagi S, Marques $\mathrm{MM}$. Adhesion and growth of cultured human gingival fibroblasts on periodontally involved root surfaces treated by Er:YAG laser. J Periodontol 2003;74:1368-1375.

40. Rich A, Harris AK. Anomalous preferences of cultured macrophages for hydrophobic and roughened substrata. J Cell Sci 1981;50:1-7.

41. Eriksson C, Lausmaa J, Nygren H. Interactions between human whole blood and modified TiO2-surfaces: influence of surface topography and oxide thickness on leukocyte adhesion and activation. Biomaterials 2001;22:1987-1996. 